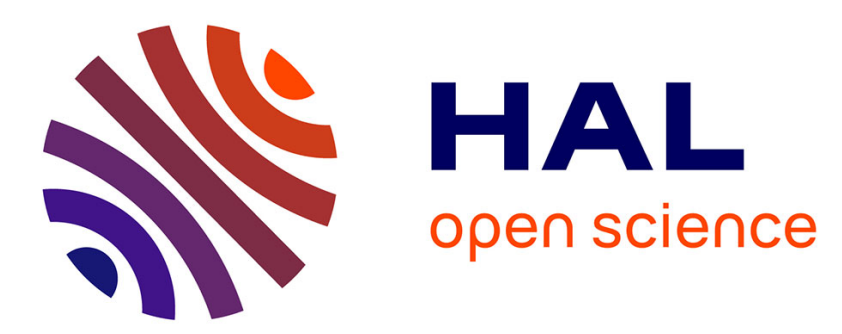

\title{
CHEMICAL VAPOR INFILTRATION OF 3D FIBROUS CARBON PREFORMS BY ZIRCONIUM CARBIDE
}

\author{
M. Nadal, F. Teyssandier
}

\section{- To cite this version:}

M. Nadal, F. Teyssandier. CHEMICAL VAPOR INFILTRATION OF 3D FIBROUS CARBON PREFORMS BY ZIRCONIUM CARBIDE. Journal de Physique IV Proceedings, 1991, 02 (C2), pp.C2705-C2-711. 10.1051/jp4:1991285 . jpa-00249876

\section{HAL Id: jpa-00249876 https://hal.science/jpa-00249876}

Submitted on 1 Jan 1991

HAL is a multi-disciplinary open access archive for the deposit and dissemination of scientific research documents, whether they are published or not. The documents may come from teaching and research institutions in France or abroad, or from public or private research centers.
L'archive ouverte pluridisciplinaire HAL, est destinée au dépôt et à la diffusion de documents scientifiques de niveau recherche, publiés ou non, émanant des établissements d'enseignement et de recherche français ou étrangers, des laboratoires publics ou privés. 
Colloque C2, suppl. au Journal de Physique II, Vol. 1, septembre 1991

\title{
CHEMICAL VAPOR INFILTRATION OF 3D FIBROUS CARBON PREFORMS BY ZIRCONIUM
} CARBIDE

\author{
M. NADAL and F. TEYSSANDIER \\ CNRS, Institut de Science et de Génie des Materiaux et \\ Procédés, Université, avenue de Vilieneuve, F-66860 Perpignan \\ cedex, France
}

\begin{abstract}
The purpose of this paper is to study the infiltration efficiency of the process in the case of $\mathrm{ZrC}$ obtained from a $\mathrm{ZrCl}_{4}-\mathrm{CH}_{4}-\mathrm{H}_{2}$ initial gas mixture. 3D carbon preforms are infiltrated for 8 hours in a hot wall reactor. An experimental design is used to determine the influence of the main factors such as temperature, total pressure and the hydrogen flow rate. The mass increase, as well as the distribution profile of the $\mathrm{ZrC}$ infiltration on a cross section of the sample, are measured for each of the eight conditions of a complete factorial design $2^{3}$. After quantification of the penetration depth of the $\mathrm{ZrC}$ coating into the preform both responses are fitted by a polynomial expression. The resulting response surfaces are presented and discussed.
\end{abstract}

\section{INTRODUCTION}

Carbon-carbon composite materials obtained either by liquid or by gaseous infiltration present many interesting features such as low density, high strength even at high temperature, high thermal conductivity and refractivity. These materials have been successfully used as brake discs, nozzles or nose tips in automobiles, aeroplanes... In order to extend these application fields and, especially, to improve their thermomechanical properties and oxidation resistance, the carbon matrix has been replaced by ceramic materials such as $\mathrm{TiC}, \mathrm{SiC}[1], \mathrm{B} 4 \mathrm{C}$ [2] or $\mathrm{BN}$ [3] infiltrated from a gas phase. Due to its thermal stability and its very high refractivity $\mathrm{ZrC}$ is an attractive material as a matrix component.

The fundamental phenomena involved in classical isothermal/isobaric chemical vapor infiltration (ICVI) are known [4-6]. The critical step is the transport of gaseous reactants by diffusion along the pore. In order to prevent the formation of voids resulting from an early sealing of the pore entrance, the deposition process must be kinetically ratelimited by the surface reactions. This condition is fulfilled at both low temperature and pressure. Several models give realistic results [7-8], but the main difficulty lies in the diffusion (ordinary or Knudsen) modelling in a well described porous medium [9-10]. Nevertheless, due to the lack of reliable data on kinetics of complex chemical systems such as $\mathrm{ZrCl}_{4}-\mathrm{CH}_{4}-\mathrm{H}_{2}$, the best processing conditions have to be experimentally determined. 


\section{EXPERIMENTAL DEVICE}

Experiments were carried out in the hot wall reactor shown in figure 1. The reactor is composed of an alumina tube disposed vertically. The 3D fibrous carbon preforms supplied by the "Societe Européenne de Propulsion" have a parallelepipedic shape 60:20:9 mm. The initial gas mixture is composed of $\mathrm{ZrCl}_{4}-\mathrm{CH}_{4}-\mathrm{H}_{2}$. The carrier gas (hydrogen) as well as the methane flow rates are controlled by means of massflowmeters. The main problem lies in the zirconium solid precursor. Zirconium tetrachloride is a white powder (density $=2.73$ ) presenting a low vapor pressure: $\log \mathrm{P}($ torr $)=11.741-5390 / \mathrm{T}(\mathrm{K})(480-690 \mathrm{~K})$ [11]. This powder is sublimed in a crucible located at the bottom of the reactor at a position where the temperature is still high enough to prevent condensation of $\mathrm{ZrCl}_{4}$. This crucible, equipped with a thermocouple is heated up to $473 \mathrm{~K}$ by a resistor wrapped around it. In order to prevent extra heating of the compound by radiation, the receiving crucible is covered by a lid with a hole (diam $=1 \mathrm{~mm}$ ) drilled in the middle. Under experimental conditions (Table 1) the measured rate of vaporization of $\mathrm{ZrCl}_{4}$ is $2.10^{-3} \mathrm{~mole} / \mathrm{h}$ ( $\mathrm{T}$ vaporizer $=200^{\circ} \mathrm{C}$ ). The molar fraction of methane is fixed to $1.10^{-2}$.

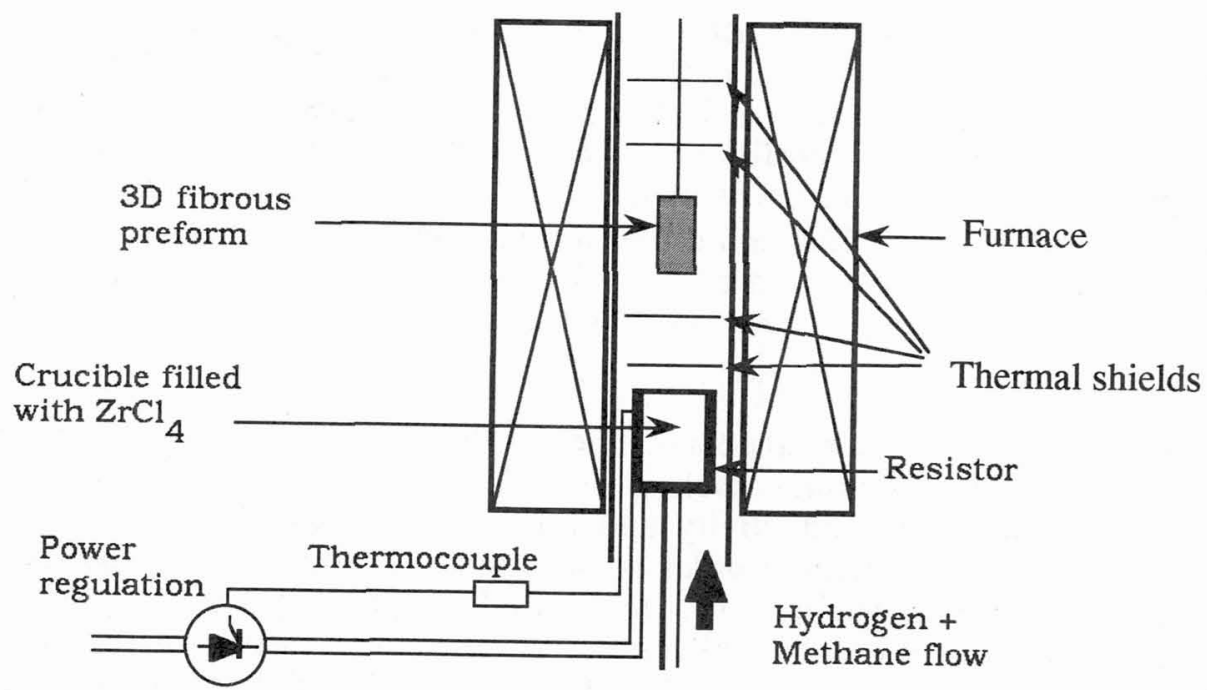

FIGURE 1: Experimental arrangement.

\section{EXPERIMENTAL DESIGN}

An efficient method means one which obtains the required information and degree of precision with the minimum expenditure of effort. An experimental. design allows the determination of the effect of each factor in the analysis of the experimental results with the same accuracy as if only one factor had been varied at a time, and the effects of interaction between the factors can also be evaluated.

Three main factors are known to have a significant influence on infiltration behavior: temperature, total pressure and flow rate of the initial gas mixture. The influence of these parameters on the mass increase, as well as the distribution profile of the $\mathrm{ZrC}$ infiltration into the sample are studied. A full $2^{3}$ factorial design is used which requires 
all combinations of two versions of each of the 3 variables, that is to say eight runs. For the three continuous variables the two versions become the high and the low level of that variable respectively identified by a plus and minus sign. This $2^{3}$ factorial will provide the eight vertices of a cube in a three-dimensional coordinate system. The domain of variation of each parameter is chosen according to previous experiments or results from the literature and is summarised in table 1.

TABLE 1: Experimental values of the variables used for the factorial design. Concentration is constant.

\begin{tabular}{|c|c|c|c|}
\hline & $\begin{array}{c}\text { TEMPERATURE } \\
\text { T (K) }\end{array}$ & $\begin{array}{c}\text { TOTAL } \\
\text { PRESSURE } \\
\text { P (mbar) }\end{array}$ & $\begin{array}{c}\text { FLOW-RATE } \\
\text { (standard 1/h) } \\
\text { D }\end{array}$ \\
\hline LEVEL - & 1273 & 10 & 10 \\
\hline LEVEL + & 1373 & 50 & $\mathbf{4 0}$ \\
\hline
\end{tabular}

\section{RESULTS}

The preform is maintained at the infiltration temperature for 8 hours. No mass loss is observed after such a heat-treatment under pure hydrogen. Each sample is characterized by its mass increase, its morphological appearance observed by SEM and the depth profile of zirconium carbide infiltration. This last feature is determined from the zirconium line-profile achieved by EDS on a cross section of the preform. The EDS signal is not corrected and only gives the penetration depth. Two examples are presented in figure 2 . In order to take advantage of this measurement for the experimental design this response has been quantified. For that purpose, an infiltration coefficient is defined (I) as the penetration depth divided by the half thickness of the sample $(4.5 \mathrm{~mm})$. The response then varies between 0 , when no infiltration occurs, and 1 , when the fibres throughout the sample are coated.

Outer surface

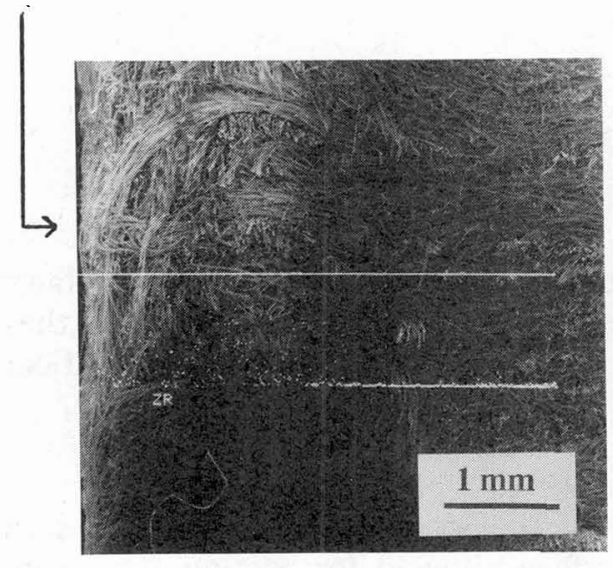

Sample 1

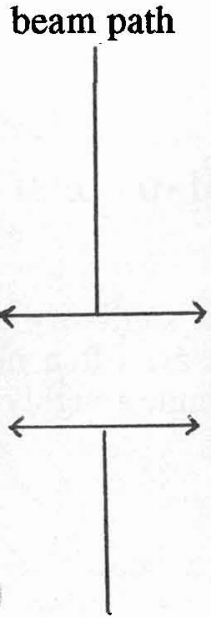

$\mathrm{Zr}$ signal

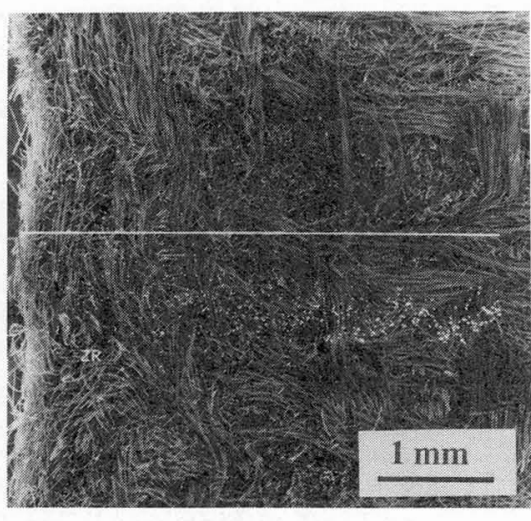

Sample 4

FIGURE 2: EDS line-profile of zirconium on the cross section of samples 
The fibrous preform is a soft material and therefore difficult to cut in a reproducible way. In consequence, a slight dispersion is observed in the initial mass of the samples. In order to minimise the bias resulting from this scattering, the mass increase divided by the initial mass of the sample $\left(\Delta \mathrm{P} / \mathrm{P}^{\circ}\right)$ is taken into account for the statistical analysis. All these results are presented in table 2 .

TABLE 2: Mass increase and coefficient of infiltration of the samples according to the experimental conditions.

\begin{tabular}{|c|c|c|c|c|c|c|}
\hline SAMPLE & $\mathbf{T}$ & $\mathbf{P}$ & $\mathbf{D}$ & $\begin{array}{c}\text { MASS } \\
\text { INCREASE } \\
\Delta \mathbf{P} \text { mg }\end{array}$ & $\begin{array}{c}\Delta \mathbf{P} / \mathbf{P}^{\circ} \\
\mathbf{M}\end{array}$ & $\begin{array}{c}\text { INFIL. } \\
\text { coef. } \\
\text { I }\end{array}$ \\
\hline 1 & - & - & - & 208 & 44 & 1 \\
\hline 2 & + & - & - & 585 & 124 & 0.62 \\
\hline 3 & - & + & - & $\mathbf{4 2 5}$ & 93 & 1 \\
\hline 4 & + & + & - & 218 & 58 & 0.11 \\
\hline 5 & - & - & + & 127 & 32 & 0.53 \\
\hline 6 & + & - & + & 641 & 139 & 0.47 \\
\hline 7 & - & + & + & 267 & 64 & 1 \\
\hline 8 & + & + & + & 567 & 127 & 0.4 \\
\hline
\end{tabular}

Two response surfaces are obtained by multiple regression analysis. As second order square terms cannot be estimated from a two-level factorial design the polynomial models only include cross-product variables:

Normalized mass increase $\triangle \mathrm{P} / \mathrm{P}^{\circ}$ :

$\mathbf{M}=85.13+26.88 * \mathbf{T}+0.38 * \mathbf{P}+5.38 * \mathbf{D}-19.87 * \mathbf{T} * \mathbf{P}+4.63 * \mathbf{P} * \mathbf{D}+15.63 * \mathbf{T} * \mathbf{D}$ $+8.88 * \mathrm{~T} * \mathbf{P} * \mathrm{D}$

Coefficient of infiltration: $\mathbf{I}=0.641-0.241 * \mathbf{T}-0.014 * \mathbf{P}-0.041 * \mathbf{D}-0.131 * \mathbf{T} * \mathbf{P}+0.114 * \mathbf{P} * \mathbf{D}+0.076 * \mathbf{T} * \mathbf{D}$ $-0.004 * \mathbf{T} * \mathbf{P} * \mathbf{D}$

In the conditions of smoothness and similarity commonly encountered, the three-factor and multi-factor interaction effects are often negligible. Under this assumption these terms are sometimes used to determine roughly the coefficients which are significant from a statistical point of view.

\section{DISCUSSION}

This response is the result of two contributions: the growth rate of $\mathrm{ZrC}$ and the infiltration depth which modifies the effective surface allowed for coating. These two contributions may not have the same dependence on the three parameters and will be discussed. 

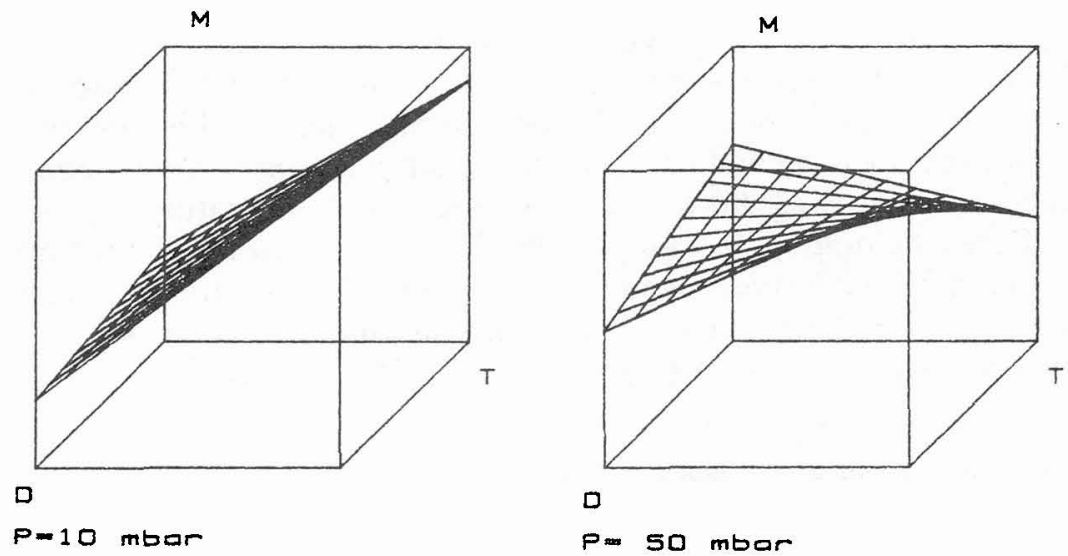

FIGURE 3: Response surface of the mass increase. (M)

$D=$ flow rate, $T=$ temperature

The behavior observed under 10 mbar is typical of a process controlled by surface reactions: the deposition rate is not dependent on the flow-rate but strongly increases with temperature. Under 50 mbar total pressure this behavior is modified and a coupling effect between $D$ and $T$ is observed. The enhancement of the deposition rate still present at high flow-rate is no longer observed at $10 \mathrm{l} / \mathrm{h}$. This unexpected behavior may result from the strong decrease of the infiltration process figure 4 . Whereas the whole sample is infiltrated at low temperature, only $10 \%$ of the fibres are coated at high temperature, leading to a reduced coating surface.
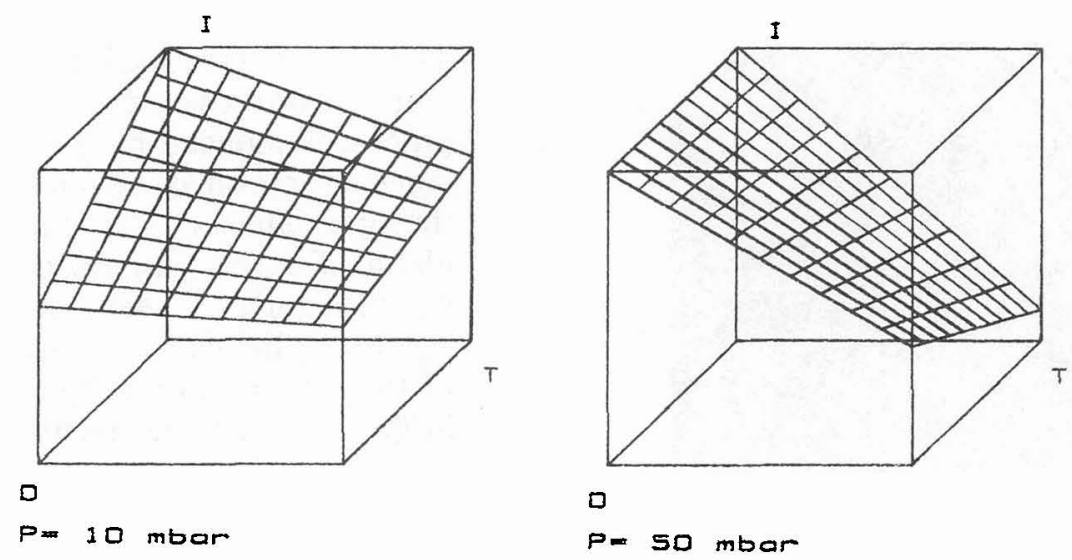

FIGURE 4: Response surface of the infiltration coefficient. (I) $\mathrm{D}=$ flow rate, $\mathrm{T}=$ temperature

Temperature is obviously the most important factor.Total pressure seems to have almost no influence but this phenomenon may be related to the narrow range of variation considered in this study. The strong influence of temperature results from the exponential dependence of the chemical kinetics and is an indication of a kinetic process controlled by surface reactions. This behavior is clearly seen on figure 3 . 
Figure 4 also shows that whatever the flow-rate or the total pressure, the high temperature always lowers the infiltration efficiency, which is the reason for the negative coefficient of this factor in the polynomial model. This phenomenon is more pronounced at high pressure and confirms models predicting favored deposition near the pore entrance when raising both total pressure and temperature. SEM observations reveal that fibres belonging to samples having a coefficient of infiltration of 1 are uniformly coated by $\mathrm{ZrC}$ layers which can be very thin but are uninterrupted (figure 5). In the other cases the fibres located in the intermediate zone where the infiltration process stops are partially covered by small $\mathrm{ZrC}$ islets (figure 6).

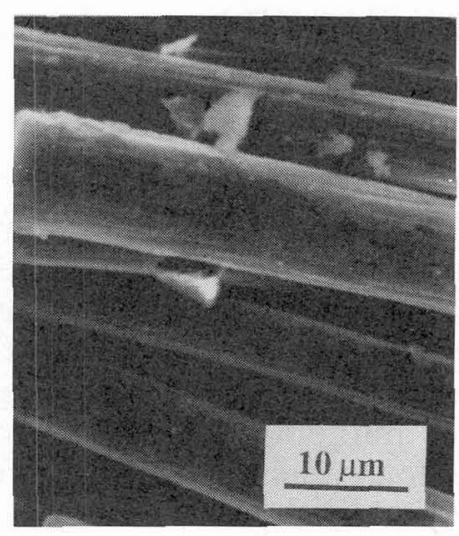

SEM observation of fibres FIGURE 5: sample 1

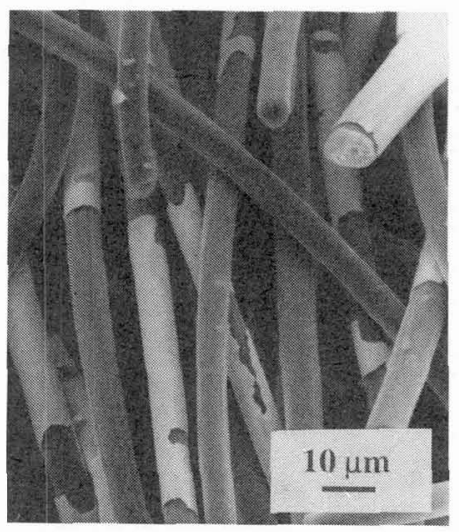

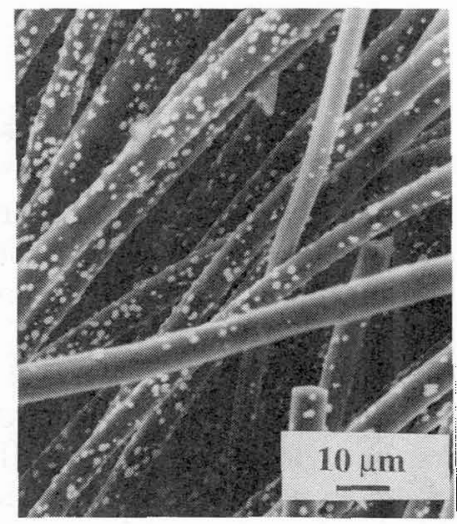

FIGURE 6: sample 4

These two types of behaviour may result from two distinct nucleation processes induced by the difference in supersaturation of reactive species in the gas phase. The thick coatings obtained in this case on fibres near the sample surface seem to be weekly bonded to the carbon substrate because of their deterioration by scaling effect in the cutting zone (figure 7).

FIGURE 7: SEM observation of fibres (sample 4)

\section{CONCLUSION}

The conditions for the infiltration of 3D fibrous carbon preforms have been investigated with the use of a factorial experimental design. Of the three parameters studied, temperature is the most important. The fibres are coated throughout the sample in almost all conditions at $1273 \mathrm{~K}$ though this is never the case at $1373 \mathrm{~K}$. The influence of total pressure, both on the mass increase and the infiltration process, is very low and 
may perhaps be a consequence of the narrow range considered here: $10-50$ mbar. The maximum mass increase observed when fibres are coated throughout the sample is obtained for the following experimental conditions: $T=1273 \mathrm{~K}, \mathrm{P}=50 \mathrm{mbar}, \mathrm{D}=10 \mathrm{l} / \mathrm{h}$. According to the tendency within the experimental domain an increase of the deposition rate may be obtained by raising total pressure. This result corresponds to the best conditions after eight hours but will not necessarily be the conditions giving the best final result i.e. the smallest residual voids.

\section{ACKOWLEDGEMENTS}

The authors wish to thank Société Européenne de Propulsion (Bordeaux) for its financial support and carbon preform supply.

\section{REFERENCES}

/1/ Naslain R., Rossignol J.Y., Hagenmuller P., Christin F., Heraud L., Choury J.J., Revue de Chimie minérale, 18,5 (1981) 544.

12) Hannache H., Langlais F., Naslain R.,

Proc. of the V Euro. Conf. on CVD, Carlsson J.O., Lindstrom J. (Eds), Upsalla SWEDEN, (1985) 219.

3/ Gebhardt J.J.,

Proc. of the IV Intern. Conf. on CVD, Wakefield G.F. , Blocher J.M. (Eds), Boston USA, (1973) 460.

14/ Naslain R., Langlais F., Fedou R.,

Proc. of the VII Euro. Conf. on CVD, Ducarroir M. , Bernard C. , Vandenbulcke L. (Eds), Perpignan FRANCE, (1989) 191.

15/ Stinton D.P.,

Proc. of the X Intern. Conf. on CVD,Cullen G.W. , Blocher J.M. (Eds), Honolulu USA, (1987) 1028.

16/ Besmann T.M., Lowden R.A., Sheldon B.W., Stinton D.P., Proc. of the XI Intern. Conf. on CVD, Cullen G.W. , Spear K.E. (Eds), Seattle USA, (1990) 482.

/7/ Tai N.H., Chou T.W., J.Am.Ceram.Soc., 72,3 (1989) 414.

18/ Fedou R., Langlais F., Naslain R.,

Proc. of the XI Intern. Conf. on CVD, Cullen G.W. , Spear K.E. (Eds), Seattle USA, (1990) 513.

19/ Gupte S.M., Tsamopoulos J.A., J.Electrochem.Soc., 137, 5 (1990) 1626.

/10/ R.R.Melkote, K.F.Jensen, AIChE J., 35,12 (1989) 1942.

/11/ P.Pascal, Nouveau traité de Chimie Minérale, IX, Masson Ed. (1963) 533. 